Technical Paper

\title{
Study on Adopting Measuring Technology(CAT) for Producing Automotive Closure Parts
}

\author{
Kazuo Muto ${ }^{1)}$ Katsushi Fuke ${ }^{2)}$ Hajime Nakamura ${ }^{3)}$ \\ 1) Shizuoka Institute of Science and Technology, Mechanical Engineering \\ 2200-2 Toyosawa, Fukuroi, Shizuokao, 437-8555 Japan (E-mail: kmuto@me.sist.ac.jp) \\ 2)-3) Hirotec Corporation Co., Ltd. \\ 5-2-1 Ishiuchiminami, Saeki-ku, Hiroshima 731-5197, Japan (E-mail: is_sakai@ftr.co.jp)
}

Received on August 27, 2010

Presented at the JSAE Annual Congress on May 19, 2010

\begin{abstract}
This paper descries the measuring technology, so-called CAT (Computer Aided Testing) technology which is the most important to design and manufacture of automotive closure parts, such as doors, exhausts systems and its production equipment, to give feedback know-how of operations into the design of product and assembly equipment and leading engineering innovation in manufacturing, and to make use as feedback CAT data for correcting the error margins at other each process, such as CAD, CAE, CAM,. As a result, we could establish the optimal manufacturing system and produce excellent products in quality, delivery, and cost.
\end{abstract}

KEY WORDS: (Standardized) Production/Manufacture

(Free)Inspection, Measurement, Computer-aided testing ,Evaluation, Quality [D4]

\section{Introduction}

In recent years, the automotive producing technology has progressed from so-called $\mathrm{CAD} / \mathrm{CAM}$ to $\mathrm{CAD} / \mathrm{CAE} / \mathrm{CAM} / \mathrm{CAT}$ which has the feedback function that measuring data measured with CAT (Computer Aided Testing) functions as those feedback data for correcting the error margins at other each process, such as CAD, CAE, CAM. (1) For instance, though the manufactured product is made based on CAD data, it can be found out the difference for the first time to know how many error margins of an actual product exist by comparing CAD data with CAT data. By investing technical information as thsi feedback data, trouble cause could be ascertained in each process CAD (design), CAE (analysis) , CAM (manufacturing)of information on CAT as shown in Figure 1. In this sense, the most important characteristic required the automotive part company is that has been established the optimal manufacturing system with CAT technology to manufacture an excellent product in quality, delivery and cost by mining technology and know-how acquired from our comprehensive closure manufacturing activities from designing and manufacturing of products and production equipment. ${ }^{(2)}$

Therefore, we have attemptted to establish the optimal manufacturing system to manufacture an excellent product in quality, delivery and cost by mining technology and know-how acquired from our comprehensive closure manufacturing activities from designing and manufacturing of products and production equipment for several years. ${ }^{(3)}$

This paper descries the measuring, inspection and CAT activities which are the most important to design and manufacture of automotive doors, exhausts systems and its production equipment as shown in Figure 2 and to give feedback know-how of operations into the design of product and assembly equipment and leading engineering innovation in manufacturing. As a result, we could establish the optimal manufacturing system and produce excellent products in quality, deliver, and cost.

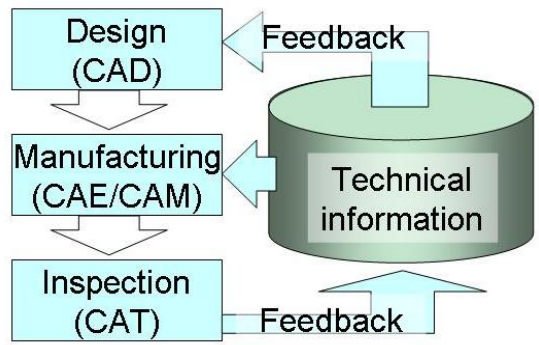

Fig. 1 Feedback CAT information to each devision

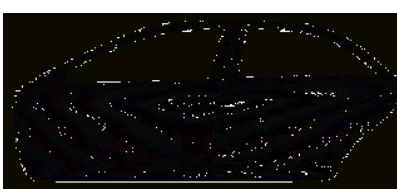

(a) Door panel (Body in White)

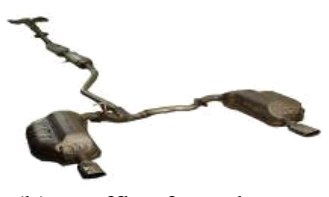

(b) Muffler for exhaust

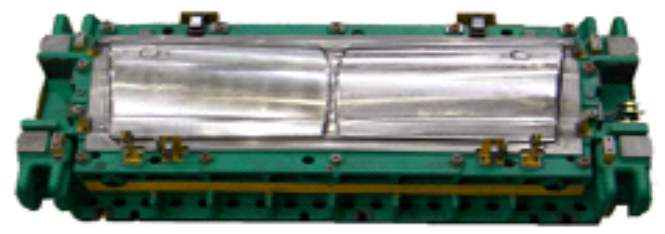

(c) Stamping Die (Door Outer)

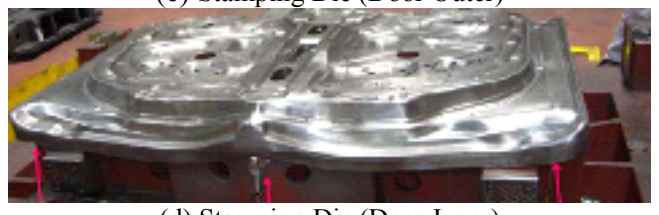

(d) Stamping Die (Door Inner)

Fig. 2 Main Products 


\section{Measuring points in manufacturing operation and purpose of measurement}

Two main qualities required for manufacturing automotive closure parts are the accuracy of a part itself size tolerance and the accuracy of appearance, which is visual quality.

The accuracy of a part itself size tolerance is generally determined by tolerances at final assembly of parts, which should be between -0.5 to $+0.5 \mathrm{~mm}$ in visual check. And the accuracy of appearance is generally determined by the smoothness of surface. Results of the accuracy will be depend on human sensuality since it is difficult to adopt measuring technology into this analog area, however, it should be between plus or minus 10 to $20 \mu \mathrm{m}$.

With the development of digital technology in recent years, the digital technology has been also utilizing in the measurement process for assembly accuracy.
This paper discrives digital measuring technologies, socalled CAT technology adopted in door design and manufacturing, purposes of using the measuring technology, some example of digitalization, and our challenge to digitalization in the area of human senses (analog).

\subsection{Design Operation}

As indicated in Table 1, design work mainly consists of 5 design operations from product design to manufacturing line design. Among these operations, production design requires the measurement. In product design, we verify the rigidity, durability, and collision safety using a prototype vehicle (an actual car).

Door rigidity is verified by the amount of sash stand out (window frame) while driving, amount of door sag when door is open, and tensile strength of a door surface. Durability strength is verified by investigating effects on parts (i.e. cracks) after

Table 1 Design Operations Contents and Points Require Measurement

\begin{tabular}{|c|c|c|}
\hline Operation & Measuring Points and Methods & Purpose \\
\hline \multicolumn{3}{|l|}{ Design Operation } \\
\hline 1 Product design & $\begin{array}{l}\text { Measurement of prototype vehicle } \\
\text { Measuring door rigidity, durability, and collision safety } \\
\text { 1. Rigidity } \\
\text { - Sash rigidity: dial gauge } \\
\text { - Door sag rigidity: dial gauge } \\
\text { - Tensile rigidity: dimple } \\
\text { 2. Durability strength } \\
\text { - Durability test of opening/closing door: counter } \\
\text { 3. Collision safety } \\
\text { - Compression test equipment: absorbed energy }\end{array}$ & $\begin{array}{l}\text { Validating design } \\
\text { (Checking Design validity) }\end{array}$ \\
\hline $\begin{array}{l}2 \text { Stamping die design } \\
3 \text { Hem die design } \\
4 \text { Weld assembly equipment design } \\
5 \text { Manufacturing line design }\end{array}$ & & \\
\hline
\end{tabular}

Table 2 Production Equipment Manufacturing Operation and Points Require Measurement

\begin{tabular}{|c|c|c|c|}
\hline & Operation & Measuring Points and Methods & Purpose \\
\hline \multicolumn{4}{|c|}{ Assembly Equipment Manufacturing } \\
\hline & 1 Press die manufacturing & & \\
\hline \multirow[t]{6}{*}{$* 1$} & 1) Casting cutting & $\begin{array}{l}\text { Measure casting with noncontact 3D measuring } \\
\text { machine and develop NC machining data }\end{array}$ & Reducing machining time \\
\hline & 2) Machining & Develop cutter pass by using noncontact 3D & Reducing machining time \\
\hline & & measuring data and CAD data. & Preventing blade damage \\
\hline & & & $\begin{array}{l}\text { Realization of unmanned } \\
\text { operation }\end{array}$ \\
\hline & 3) Assembly & Measuring assembly accuracy by using CMM & Accuracy inspection \\
\hline & 4) Heat treatment & Measuring hardness of blade and bending punch & Hardness inspection \\
\hline \multirow[t]{2}{*}{$* 2$} & 5) Tryout, tuning & Measuring operation panel by using & Check adequacy of variances \\
\hline & & noncontact 3D CMM & $\begin{array}{l}\text { \& projection between operation } \\
\text { Giving feedback to design }\end{array}$ \\
\hline \multirow[t]{3}{*}{$* 3$} & & Measuring finished panel with noncontact CMM & Accuracy inspection \\
\hline & & $\begin{array}{l}\text { Measuring tried out dies with noncontact CMM } \\
\text { (Comparing with CAD Data) }\end{array}$ & $\begin{array}{l}\text { Reducing tryout time by giving } \\
\text { feedback to design after } \\
\text { checking projection amount }\end{array}$ \\
\hline & $\begin{array}{l}2 \text { Assembly (Weld) Equipment } \\
\text { Manufacturing }\end{array}$ & $\begin{array}{l}\text { Measure positions of standard locating face and } \\
\text { locating pin for assembly equipment with CMM }\end{array}$ & $\begin{array}{l}\text { Accuracy assurance } \\
\text { of part assembly }\end{array}$ \\
\hline
\end{tabular}

*1 The adaption of noncontact measuring machine at casting machining operation.

*2 The adaption of noncontact measuring machine to assess the variances between each press operations.

*3 The adaption of noncontact 3D measuring machine for analyzing distortion on a door form. 
repeating opening and closing doors with specified conditions. Collision safety is verified by measuring amount and condition of deformation after adding compressive load from door side with specified conditions. Table 1 indicates the operation, and points and methods of measuring, and its purposes.

\subsection{Manufacturing production equipment}

As indicated in Table 2, there are two main aria of manufacturing production equipments for stamping dies and assembly. In the area of stamping die manufacturing, there are 5 operations from machining of casting to tryout and tuning. Casting is processed using NC machining data which prepared based on CAD data. The accuracy of casting is usually between 5 to $+5 \mathrm{~mm}$ and can not be said well. NC machining data sets a margin to prevent interference of a tool with cutting area or to prevent cutting area become bigger than set area. As a result, air cutting which a tool is not cutting are increased and it causes a longer machining time.

Therefore, we changed the operation to measure a casting (Figure 3) with noncontact measuring machine before machining, and to develop optimum $\mathrm{NC}$ data (Figure 5) after revising original $\mathrm{NC}$ data using the measured data (Figure 4). This had achieved great effects as indicated in Table 3. Machining time is reduced by $40 \%$ due to the decrease of a tool air cutting. The unattended operation of the machine becomes possible due to no more interference of a tool and a casting.

In Table 2, we summarized the measuring points, measuring method and purpose of measuring. And “*”mark is examples of digitalization. Normally, number of press operations to complete door parts are 3 to 4 processes, such as drawing, trimming, bending. Shift-bending Accuracy of a part is usually measured with a checking fixture. In this method in the past, since only the result of a measurement of the final process is understood final processed parts, there is a problem that we cannot assess the passage of the part qualit at each operation on the way. As a result, die hand finishing for each operation requires a hunch and experiences of skilled workers. We called this operation "die tryout and tuning"which takes a lot of time.

Therefore, we measured panels from each operation with noncontact 3D measuring machine (Figure $6^{(4)}$, VECTRONVMC5546 ) which measurement accuracy is $2 \sigma: \pm 0.06 \mathrm{~mm}$, and tried to quantify the amount of variances numerically (Figure 7) . By giving feedback meseared 3D data to die design, we analyzed successfully the relationship between the amounts of variances at operation and projection. As a result, die hand finishing operation by skilled workers has been reduced.
Quality of appearance is very important for a door. However, especially the generation of distortions around drawing door handle area is inevitable problems for press forming. Traditionally, die tryout and tuning have been repeatedly conducted by the skilled workers to reduce distortions. This operation, the final finishing of die manufacturing, is the most significant operation that takes a lots of time.

So, we compared the shape of a tuned die and a panel by using the noncontact 3D measuring machine and quantified numericaly the relationship between dies and panels. Futhermore, we have successfully projected the shape which is hard to generate distortions by giving feedback to CAD data in the die design. With the success of $* 2$, we have reduced time to die tryout and tuning by $70 \%$.

Figure 8 indicates the measurement data of distortions generated in regular press forming. Distortions are generated in red area. Figure 9 shows a press formed panel that shape is projected and distortions that are reduced. As a result: because where to be corrected had been creared, man-hour of die tryout and tuning is reduced by $70 \%$

\subsection{Quality Improvement of a Part}

As shown in Table 4, quality improvement of a part has two fields which are press part single goods and Assembly part (product that assembled them). For quality improvements of press part single goods, a part from final process is measured and inspected with a checking fixture. As previously explained about die manufacturing, part quality is firmed with the accuracy of dies, therefore, it is assumed that importance of measurement is low.

Assembly part is also measured and inspected with a checking fixture. For a door usually consist of 15 components, tolerance of component itself and the accuracy of welding equipment have a great impact to quality of a finished part. Consequently, measurement of assembly part is very significant. In this field, we recognize the necessity of operation reform by digitization in the future.

Table 3 Effect by non-contact 3D meseament in machinining operation

\footnotetext{
(1) Air cut of machining is reduced; machining time is reduced by $40 \%$

(2) Prevent the interference of a tool and casting

(3) Unmanned operation became possible
}

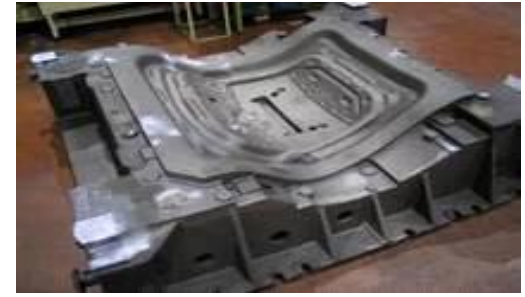

Fig.3 Casting (before machining)

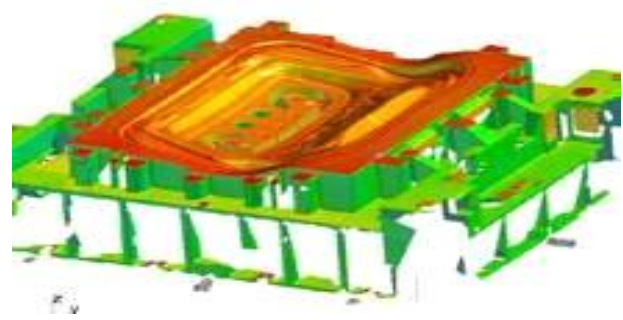

Fig.4 Result of casting measurement (3D CAD data)

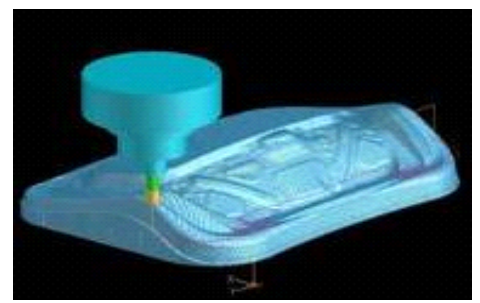

Fig.5 NC Machining Data (3DCAM CL data) 
Table 4 indicates specifically the operation, and points and methods of measuring, and its purposes.

\subsection{Press Operation}

In press operations as indicated in Table 5, there are inline inspection which inspect a part directly in a production line and offline inspection which inspect a part by sampling on regular

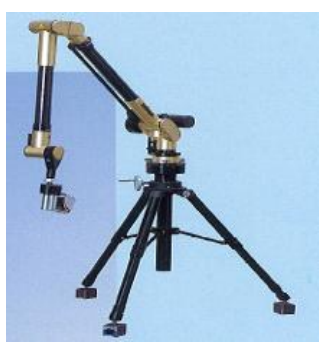

(a)appearance

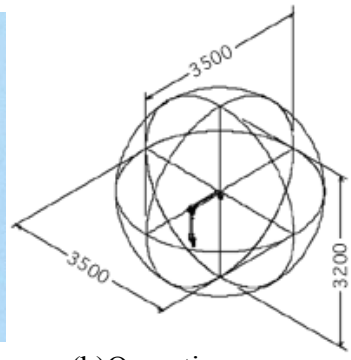

(b)Operating range
Fig. 6 Noncontact 3D CMM (VECTRON-VMC5500 Serie)

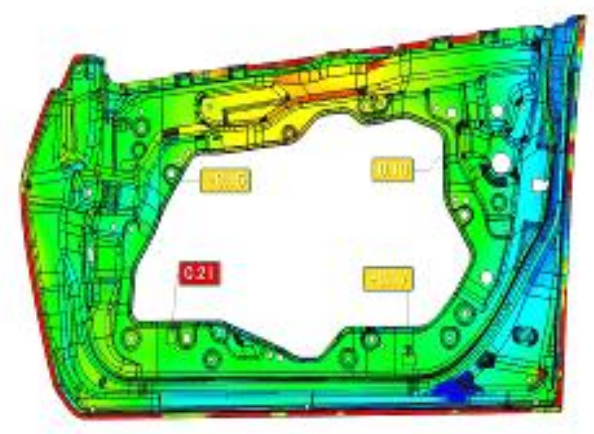

Fig. 7 Noncontact 3D measuring data basis. In inline inspection, we visually determine appearances, mainly scratches on a surface and cracks generated by forming.

Due to the fact that inline inspection has to be done in very short time (usually within 3 seconds), inspection becomes very limited. This is the field requires automatic measurement. Once a quality defect failure is occurred, we face the problem that we mistakenly manufacture defective parts until they are found. Therefore, measurement technology innovation at line inspection is desirable in the future.

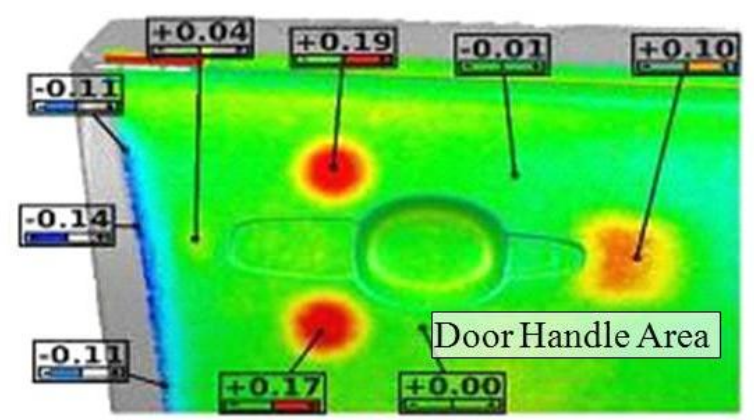

Fig. 8 Panel measurement data without projection

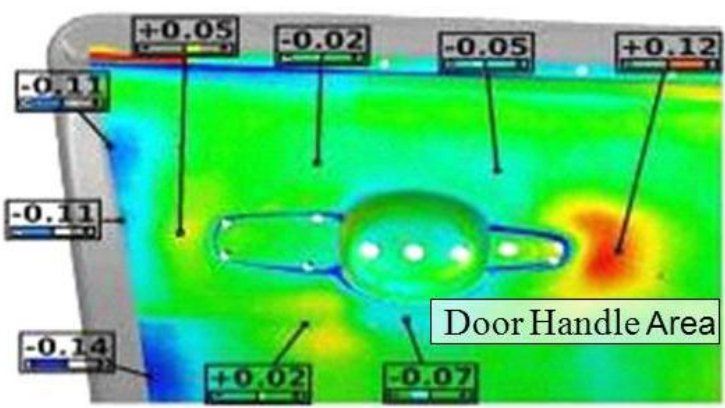

Fig. 9 Panel measurement data with projection

Table 4 Parts quality improvement and points require measurement

\begin{tabular}{c|l|l}
\hline \hline \multicolumn{1}{c|}{ Operation } & \multicolumn{1}{|c}{ Measuring Points and Methods } & \multicolumn{1}{c}{ Purpose } \\
\hline \begin{tabular}{|l|l|l} 
Quality improvement of parts \\
of press parts
\end{tabular} & $\begin{array}{l}\text { Measuring location of hole and surface location } \\
\text { and trim edge with caliper, dial gauge and other tools. } \\
\text { Chekcing Surface quality, crack, necking, and } \\
\text { distortion by visual check }\end{array}$ & $\begin{array}{l}\text { Quality Inspection } \\
\text { Indicating correction value } \\
\text { Indicating correction point }\end{array}$ \\
\hline $\begin{array}{l}\text { 2 Quality Improvement of } \\
\text { Assembly parts (Door) }\end{array}$ & $\begin{array}{l}\text { Setting a door to a checking fixture and measure gap } \\
\text { and flushness with caliper, dial gauge, etc. }\end{array}$ & $\begin{array}{l}\text { Quality Inspection } \\
\text { Indicating correction value } \\
\text { Indicating correction point }\end{array}$ \\
\hline
\end{tabular}

Table 5 Inspections at stamping operation and points require measurement

\begin{tabular}{|c|c|c|}
\hline Operation & Measuring Points and Methods & Purpose \\
\hline \multicolumn{3}{|l|}{ Press } \\
\hline $\begin{array}{c}1 \text { In line inspection (3 seconds) } \\
\text { Dent and projection }\end{array}$ & Detecting surface defects by hand grinding & Quality Inspection \\
\hline 2 Off line inspection & & Quality Inspection \\
\hline Crack, necking & Visually checking the decrease in panel thickness & Quality Inspection \\
\hline Distortion & Check with hand grinding, or visual check & \\
\hline Dimension & $\begin{array}{l}\text { Measuring location of hole and surface location } \\
\text { and trim edge, with caliper, dial gauge, etc. }\end{array}$ & Quality Inspection \\
\hline
\end{tabular}


Table 6 Inspections at assembly operations and points require measurement

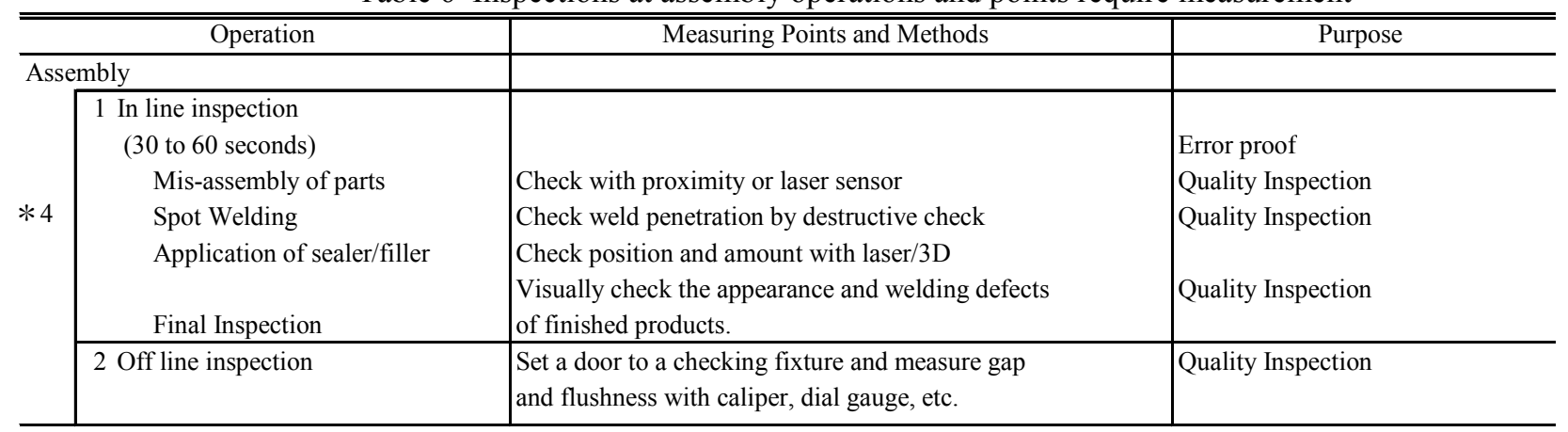

:*4 The CCD Camera for quality inspection of sealer and filler application.

In offline inspection, we inspect decrease ratio of panel thickness and dimensional accuracy in addition to the appearanceaccuracy. This is important operation to prevent manufacturing defective parts. Since limitation of inspection time is lesser than inline inspection, offline inspection is gradually digitalizing by adapting noncontact $3 \mathrm{D}$ camera, etc.

Table 5 shows the operation, and points and methods of measuring, and its purposes in detail.

\subsection{Assembly Operation}

In assembly operations as well as the press operation as shown in Table 6, there are inline inspection which inspect a part directly in a production line and offline inspection which inspect a part by sampling on regular basis. Laser and 3D camera are adopted in measurements.

In inline inspection, there are measurements checking direction, location and type of a part to prevent misassembly.Also measurement and inspection to determine condition of spot weld penetration is conducted periodically in line. Limited teardown check or destructive check (primitive but reliable method) is conducted by checking condition of penetration by inserting a chisel into welded area. In the future, digitalization of inspection in material such as adapting ultrasonic wave is desirable to make a highly accurate judgment in a short time. In addition, we apply sealer to the door hem for rust proof. And, we apply filler between outer panel and inner reinforcement parts to prevent vibration and contact strengthly. It is very important to control the location and amount of these applications. Previously, they were check visually by a man. Since measurement and inspection with CCD Camera are adapted, quality has been significantly improved by detecting small variances of sealer amount and sealer location. (Figure $10^{(5)}$ )

In offline inspection, we measure the assembly accuracy by setting a door to a checking fixture. Dial gauges and calipers are used for measurements. As previously described, we recognize the necessity of digitization to link withquality improvement of assembly parts.
Table 6 indicates the operation, and points and methods of measuring, and its purposes. To prevent rust and vibration of doors, sealers are applied to hem area where outer and inner panels are joined together by hemming a panel and fillers are applied to inner reinforcement parts automatically. Due to the dislocation or discontinuity of sealer or filler, there are risks that rust or vibration sounds are generated.

Therefore, all assembly parts are required to be inspected. Figure 10 shows the location and size of application. Using a CCD Camera, assembly parts are compared and checked with each and every picture shows the regular position and size toevaluate irregulars. It became possible to control them in millimeter basis, and led to the significant quality improvement.

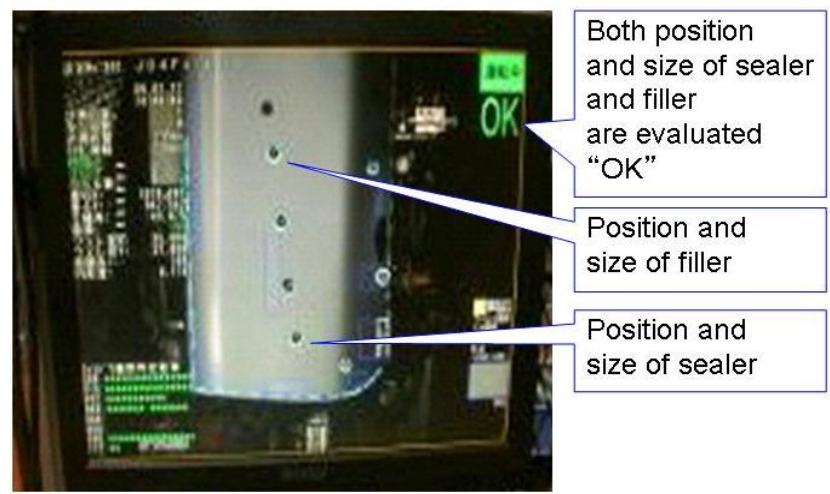

Fig. 10 Quality inspection by CCD Camera

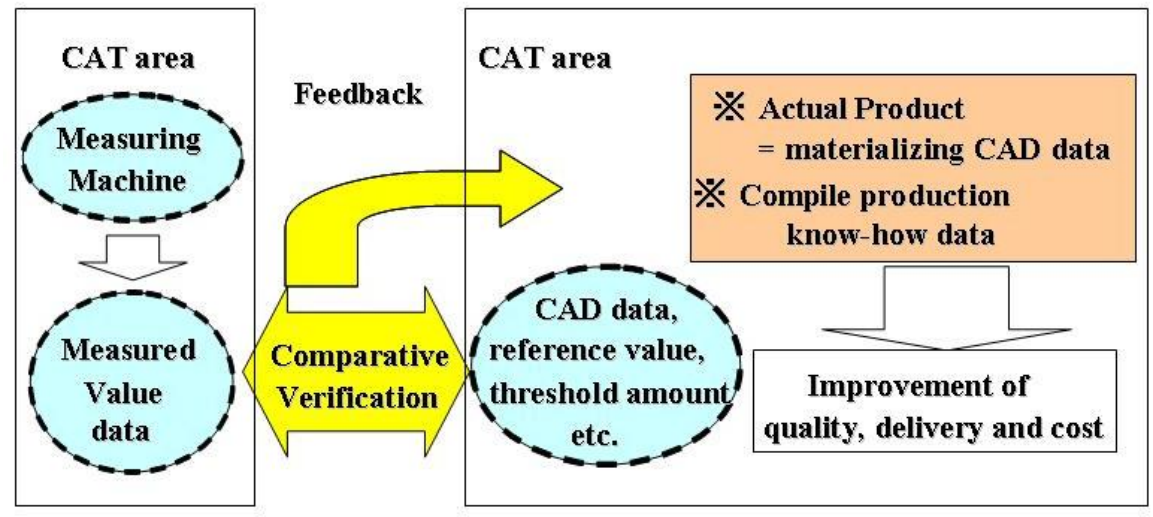

Fig.11 Comparative verification on data 


\section{Consideration}

As we investigated, we are entering a period of great changes by digitalization of measuring technology in manufacturing industry. What will be the key to lead changes? It is comparative verification of data (Figure 11).

By repeating giving feedback to next design about comparative verification result of data from design, standard, threshold amount and actual part, we believe know-how which normally relied on hunches or experiences of skilled workers will be digitalized and products will be manufactured in accordance with CAD data in the future.

\subsection{Future Digitalization Plan}

a) Adopting noncontact 3D measuring machine for quality improvement of door: Pointing out correction by improving the panel accuracy to link with the digitization of design operation.

b) Measuring crack or necking after press forming by using a sensor: Preventing generation or outflow of defectives part by checking cracks instantly in inline inspection.

c) Detecting scratch on surface with CCD Camera: Preventing generation or outflow of defective parts by detecting tiny scratches in inline inspection.

d) Improving accuracy of forming simulation with CCD Camera: Leading improvement of die design accuracy by giving feedback to CAE (simulation analysis) about any changes in forming process such as flow of material, etc.

\subsection{Challenge}

In recent years, the digital technology becomes widely used in many fields, but we consider that following improvement will be required in future expansion.

a) Improving processing speed and capability

b) Simplifying preparatory work before measurements

c) Improving reliability and completeness of software

d) Improve cost performance

\section{Conclusion}

The result of the obtained present reseach is shown as follows.

1) For example, when measuring a side panel with perception measurement, a panel is measured in laid position in many other researches. With this method, amounts of variance exceed $1 / 10 \mathrm{~mm}$ in certain areas due to panel's own weight. However in this research, a panel measurement to the direction where a panel is actually assembled in consideration for the impact of gravity is found very effective.

2) It became possible to measure dimensions at each operation (drawing, trimming, and piercing) and to compare the degree of impact at each operation. Periods required tracking the operation and modification is reduced by 10 to 20 percent. And with ATOS measurement, period of adjustment required for repairing distortions is reduced by 50 to 70 percent with the design that shapes does not produce forming distortion is incorporated into. By utilizing these measurements at the actual production, giving feedback to design and improving productivity became possible.

3) By checking locations and amounts of adhesive and mastic sealer application with a CCD camera at side panel assembly, it became possible to assure all products with the level where accuracy of location is within $1 \mathrm{~mm}$ and amount of variance is $\pm 20 \%$. Since these locations and amount could not be checked after final assembly, visual check by operator had been set in the operation. Now, we are able to eliminate the visual check. In order to secure the high product quality and productivity to meet severe requirements from customer, locations and amounts of application are checked speedy and accurately with a CCD camera.

In the field of design operation, we expect that the accuracy of parameter determed original design (CAD) date will be increased and past problems will be organized by unifying and controlling CAD data and measuring CAT data with computers.

Moreover, algorithm for designing and producting automotive closure parts will become clear.. as a result, the efficiency of operation will be promoted dramatically in coming years.

In the field of quality control, measurement with the combination of measuring machine and robot will be wildly used, and calculation of process capability or traceability will be facilitated. For example in the future, no inspector will be required in manufacturing scene.

The importance of measurement will become greater for manufacturing in the future. We expect manufacturer of measuring machine and sensor to promote further research and development of equipment and their applications which meet various environment to use them.

\section{References}

(1) K.Muto: Trend of 3Dimensional CADCAD/CAE/CAM /CAT/Network Systems and PLM System in Advanced Techno-logy for Manufacturing Engineering Development, JSAE Proceedings No.30-6, p1-6,(2006)

(2) K.Muto;First CAD/CAM,Kogyotyosakai(2004)178-195

(3) K.Fuke, H.Nakamura, K.Muto; Production Innovation by Adopting Measuring Technology for Producing Auto motive Closure Parts, Journal of JSAE,Vol.63,No.6, p8590,(2009)

(4) VECTRON(2010) http://tbts.co.jp/product/vectron/

(5) KEYENCE(2010)http://www.keyence.co.jp/gazo/index. jsp 